19 AZOTEMIA, HEMOLYTIC ANEMIA, WITH MINIMAL RENAL MICROANGIOPATHY IN A PATIENT WITH COMBINED IMMUNODEFICIENCY (CID), AND RHEOVIRUS (RV) INFECTION. Bangash, I, John, E.: Univ. of Illinots Hosptta1, ALSM, Chicago.

Hemolytic uremic syndrome (HUS) has been rarely reported in CID A 3 month old male infant presented with 3 day history of vomiting, dlarrhea, cough and $24 \mathrm{hr}$. ollgurla. Two weeks prior to this ep1sode patfent was (pt) adultted and treated for diarrhea, dehydration, ollgurea and azotem1a. On second admission pt. had $10 \%$ dehydration, actdosis and oral thrush. A normal platelet count, coombs negative hemolyt1c anemla (Hct $33 \%$, ret 1c count $25 \%$, burr cells), elevated BUN $(62 \mathrm{mg} \%)$, and creatinlne $(12 \mathrm{mg} \%)$, metabolic ac1dosis $\left(\mathrm{CO}_{2} 12 \mathrm{~mm} / 1, \mathrm{BE}-15\right), \mathrm{m} 1 \mathrm{croscop} 1 \mathrm{c}$ hematuria and proteinuria were observed on admission. Subsequently the patient developed severe thrombocytopenta, moderate anemia and decreased GFR. These changes normalized in two weeks. A chest roentgenogram revealed pneumonitis and absence of thymus gland. Immunoglobulin electrophoresis and T-cell function were consistent with CID. Stool, CSF flutd and bone marrow cultures were positive for RV. oligurla, azotemfa and hyponatremla responded to conservative therapy. How ever, pt. subsequently developed extensive dermatitis (D), generalized edema and recurrent bouts of diarrhea. Ten weeks later despite hyperalimentation and gammaglobulin therapy pt. expired. Autopsy revealed generallzed RV infection, parainfluenza pneumonitis, hypoplasia of thymus, spleen and lymph nodes, graft vs. renal histological changes seen in this pt. With other evidence of HUS $1 \mathrm{~s}$ in part due to concomitant CID, is a matter of conjuncture.

\section{DEVELOPMENTAL NEPHROLOGY}

THE RENAL RESPONSE TO CHRONIC ALKALI LOADING IN INFANTS.

50 Mathéová E.,Tischler V., Pavkovčeková 0.,Beňo P.,Fedorová E. University Children's Hospital, Košice, CSSR.

The present observations were undertaken to establish the response of infants to the chronic alkali loading for the interpretation of the abnormalities in the maintenance of acid-base homeostasis in renal tubular alkalosis.

Twelve normal infants aged 3-12 months were studied before and during 5 days of $\mathrm{NaHCO}_{3}$ administration, $157,0 \mathrm{mM} / 1,73 \mathrm{~m}^{2} /$ day. The blood acid-base parameters during alkalization showed the mild compensated metabolic alkalosis. Fractional $\mathrm{Na}$ reabsorption / $\mathrm{T}_{\mathrm{Na}} / \mathrm{F}_{\mathrm{Na}} /$ providing the indirect evaluation of the degree of ECF volum expansion remained unchanged during the alkali loading period. Urinary phl values increased to $7,278 \pm 0,202$ concomitantly with the increase of the mean fractional $\mathrm{HCO}_{3}$ excretion $\mathrm{FE}_{\mathrm{HCO}}=4,16 \pm 1,62 \%$. The changes of the means of fractional $\mathrm{HCO}_{3}$ reabsorption from the control values $\Delta \mathrm{T}_{\mathrm{HCO}_{3}}{ }^{-} \Delta \mathrm{F}_{\mathrm{HCO}} \mathrm{H}_{3}$ were $95,1 \%$ in the first day and decreased to 69,9 and $65,2 \%$ in 3 the 3 3 th and 5th loading day resp. The renal excretion of $\mathrm{H}^{+}$in both forms as $T A$ and $\mathrm{NH}_{4}^{+}$decreased during alkali loading from the mean control value of $119,5 \pm 21,9$ to $56,8 \pm 12,5 \mathrm{uM} / \mathrm{C}_{\mathrm{cr}} \cdot 100$. The renal acid-base parameters interacted with the urinary excretion of the citric acid cycle

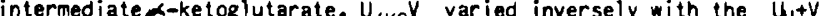
The index of the mean values of $K_{\alpha K G} V / U_{H}+V$ rosed from $0,39 \pm 0,12$ in control to $2,80 \pm 0,25 \%$ in alkali loading period.

The presented results showed the measure of the normal efficiency with which the kidney protected the organism against accumulation of excess base during chronic $\mathrm{NaHCO}_{3}$ administration in infants.

NET ACID EXCRETION DURING FIRST WEEK OF LIFE.

51 Chan, L.L., Balfe, J.W. Exen1, R., C1fuentes, R.F., Bryan, M.H. The Hospital for Sick Children. Un1 versity of Toronto, Toronto, Canada.

Metabolic acidosis occurs frequently in newborns. We have studied 34 preterm and 12 term infants during their first week of $11 \mathrm{fe}$. Twenty preterm infants were nourished with breast milk or SMA (Wyeth ${ }^{R}$ ); the remaining infants recelved total parenteral nutrition (TPN) - synthetic amino acids or casein hydrolysate solution. Net acid excretion (NAE) for breasf milk vs. SMA fed infants was $5.4+0.4$ and $7.8+0.6 \mathrm{uEq} / \mathrm{min} / \mathrm{m}^{2}$ (mean $+\mathrm{SEM}$ ). The corresponding values for the two TPN solutions in preterm infants werg significantly higher at $12.5+1.4$ and $19.4+3.5$ $\mathrm{uEq} / \mathrm{min} / \mathrm{m}^{2}$. The casein group of $\ln \mathrm{fants}$ developed acidosis with depressed plasma blcarbonate $17.4+2 \mathrm{mEq} / 1$. Term infants treated with the TPN solution produced even greater amounts of net ac1d, $20.6 \pm 2.9$ for synthetic amino acids and $35 \pm 3.7$ $\mathrm{uEq} / \mathrm{min} / \mathrm{m}^{2}$ for casein hydrolysate. Because of the net base generated from milk consumption, milk fed infants are less prone to develop metabolic acidosis. Due to 1 ts inherent acidogenic effect, TPN solutions induce acidosis more readily. Preterm infants recelving TPN are therefore required to generate a higher NAE rate compared to the milk fed infants to maintain acid-base balance. With a similar quantity of TPN intake, the te rm infants produced higher urinary ammonium, thus NAE.
¿FFECT OF INTRAVENOUS INDOMETHACIN ON RENAL FUNCTION OF PREMATURE INFANTS. John, E.G, Bhat, R., Vasan, J, Vidyasagar, D, Hastrieter, A.R. Univ. of I11. and Pres.-St. Lukes Hospital, Chicago, Illinots, U.S.A.

Ten infants with respiratory distress syndrome and large patent ductus arteriosus gestational ages 27-35 weeks, birth weights 0.9 $2.0 \mathrm{~kg}$., were treated with $0.2 \mathrm{mg} . \mathrm{kg}$ intravenous Indomethacintrihydrate (IND) given 3 times at 12 hourly intervals. Renal function tudies were performed before (T-0), 24 hours $(\mathrm{T}-24)$ and 48 hours $(T-48)$ after the first dose of IND. As shown below, the urine volumes (Uv) and glomerular filtration rates (GFR) decreased at $\mathrm{T}-24$ but returned to normal at $\mathrm{T}-48$. The fractional excretion of sodlum $(\mathrm{FENa} \%)$, urine sodium $\left(\mathrm{U}_{\mathrm{Na}}\right)$, and urine osmolarity (Uosm). were also reduced at $\mathrm{T}-24$ but decreased even further at $\mathrm{T}-48$, despite the normal GFR. There was no apprectable change in the values of serum sodfum, serum osmolarity and free-water clearance $\left(\mathrm{CH}_{2} \mathrm{O}\right)$.
$\mathrm{Uv}$

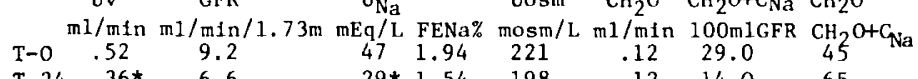

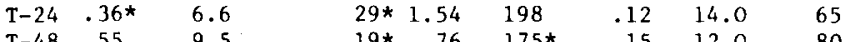
$19 * .76-175 *-15 \quad 12.0 \quad 80$

The calculated $\mathrm{CH}_{2} \mathrm{O}+\mathrm{C}_{\mathrm{Na}}$ decreased and the $\mathrm{CH}_{2} \mathrm{O} / \mathrm{CH}_{2} \mathrm{O}+\mathrm{C}_{\mathrm{Na}}$ Increased : pprectably; they measure proximal and distal tubular resorption of sodium, respect1vely. Intravenous IND appears to Increased $\mathrm{Na}$ absorption would explain the low urine sodium, and urine osmolarity. $*=\mathrm{p}<.05$

Low GFR in the early postnatal period is to a large extent due to low renal plasma flow (RPF). Since the lov RPF appears to be due mainly to active vaso-constriction, the question is raised whether renal vaso-constriction is needed to minimize the energy demands of the kidney in early postnatal life. The work load to the kidney is determined by the GFR. The most energy demanding process of the kidney is reabsorption of $\mathrm{Na}(\mathrm{TNa})$. In the present study the relationship between $\mathrm{TNa}$ and $\mathrm{D}_{2}$ consumption are compared in the immature kidney of 24 days old Fats (R24) and the mature kidney of 45 days old rats ( $R$ 45). Determinations are made of filtered $\mathrm{Na}\left(F_{\mathrm{Na}}\right), \mathrm{T}_{\mathrm{Na}}$ and $\mathrm{O}_{2}$ consumption by extraction and clearance techniques dưring hydropenia (HP) and volume expansion (VE). The two conditions are chosen since $V E$ vill cause vaso-dilatation of the immature kidney. This finding was confirmed in the present study and resulted (see table). in a marked increase of $\mathrm{TNa}$ in volume expanded R24.

\begin{tabular}{|c|c|c|c|}
\hline & TNa $\mu \mathrm{Ekv} / \mathrm{min} /$ & $\mathrm{O}_{2}$ cons $\boldsymbol{m}_{\mathrm{mol}} \mathrm{i}$ & {$\left[\begin{array}{ll}\mathrm{Na} / \mathrm{O}_{2} & \text { ratio } \\
\mu \text { ekv } & \text { mol }\end{array}\right.$} \\
\hline $45 \mathrm{HP}$ & 68.7 & 2.05 & 15.74 \\
\hline 245 VE & 73.4 & 4.69 & 1 \\
\hline $\mathrm{R} 24 \mathrm{HP}$ & 36.8 & 3.39 & 02 \\
\hline 224 VE & 76 & 4.49 & 18 \\
\hline
\end{tabular}

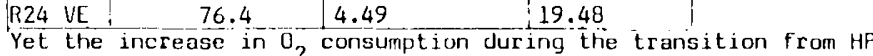
to VE was less pronounced in R24 than in R45. In volume expanded R24 the amount of $\mathrm{T}_{\mathrm{N}} / \mu \mathrm{mol}$ oxygen consumed $\left(\mathrm{Na}_{2} \mathrm{O}_{2}\right)$ increased significantly. This suggests that in the volume expanded R24 the increased tubular load of sodium is reabsorbed by non oxidative pathways, either passive or anaerobic.

COMPENSATORY ADAPTATION TO REDUCED RENAL MASS IN THE

54 NEWBORN CUINEA PIG (GP). Chevalier, R.L. Dept. Pediatrics, Univ, of Virginia, Charlottesville, VA., USA

In order to identify the physiolngic adaptation to compensatory renal hypertrophy in the newborn, right uninephrectomy (NX) or sham (S) operation was performed in GP within the first 36 hrs. of $1 \mathrm{ffe}$. At $3 \mathrm{wks}$. of age, they were studied using clearance and micropuncture techniques. Body welght (BW), left kidney weight (LKW), and arterial blood pressure (ABP) were measured. Left kidney glomerular filtration rate (IKCFR) and single nephron GFR (SNGFK) were measured by clearance of $1^{14} \mathrm{C}$ 1nulin. Proximal tulula pressure $\left(P_{T}\right)$ and stop flow pressure (SFP) were measured using a servonulling device. Glomerular capillary pressure $\left(\mathrm{P}_{\mathrm{GC}}\right)$ was estimated from the sum of SFP and collold oncotic pressure. Results (mean+SE, $\mathrm{n}=$ Number of animals, $N S=$ not significant):

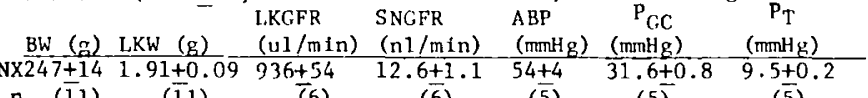

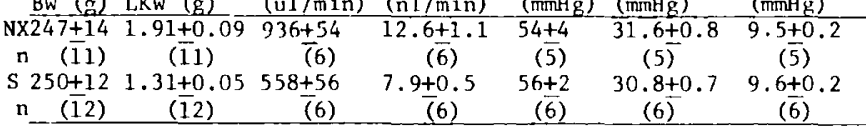

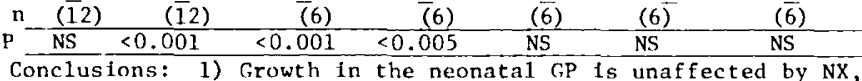
2) 3wks. following $\mathrm{NX}$, there is a $41 \%$ increase in mass and a $68 \%$ increase in GFR of the renoprival kidney, 3) There is a parallel increase in SNGFR, Indicating a significant contribution of immature superficial cortical nephrons to the adaptive process. 4) The increased SNGFR is not due to changes in $A B P, P_{G C}$, or $P_{T}$. 